\title{
Discussion of Yoga Culture and Chinese Yoga under the Background of Thought Integration
}

\author{
Min Li \\ Jiangxi Science \& Technology Normal University, Nanchang, 330013, China
}

Keywords: Thought integration, Yoga culture, Chinese yoga

\begin{abstract}
This paper mainly expounds the development of yoga at home and abroad, summarizes the connotation of Yoga culture, and points the problems in yoga based on this. Finally, it puts forward relevant suggestions and suggestions, aiming at promoting the further development of Yoga Culture in China.
\end{abstract}

In recent years, yoga in China is more and more popular. As a kind of exotic, many yoga to the culture behind and nature is fuzzy, and a clear understanding of these have important meaning for practicing yoga.

\section{Introduction of Yoga Culture}

\subsection{Origin of Yoga Culture}

"Yoga" is a word from India Sanskrit, its original meaning is referring to harmony, Yoga originated in India, which can be traced back to more than 5000 years ago in Himalaya Range area. In order to find the origin of ancient India gymnosophist people the pain and trouble to the original forest, they are going to find the true self through meditation, and in the process they inadvertently observed the nature of animals and plants in case of injury, without special cure can be self-recovery, start thinking about plants and animals are born with this self-healing, sleep or relaxation ability. After that, the practitioners established their body manners through imitation of various gestures. Besides, they began to pay attention to the breathing way, and then created the breathing method. After five thousand years of development, they evolved into the household Yoga nowadays.

\subsection{Development of Yoga Culture.}

The origin and development of yoga, the scholars have different views, but according to the development process of the standard yoga and related system perspective can be divided into six stages, they are the original stage, the Veda era, before the classical period, the classical period, after the classical period and modern period.

The first stage is the primitive period, from 30000 B.C. to fifteenth Century. The main feature of this period is that there are few written records about yoga, and the form is still reserved in the initial meditation and meditation.

The second stage is the Vida era, which refers to the difference between fifteenth Century and eighth Century. This period is different from that of the last period. It is related to the written record. It is reflected in the religious book Weidie, which describes yoga.

The third stage is the pre-classical period, that is eighth Century to fifth Century B.C., the main representative is "Upanishads", in which the records that yoga is a wonderful way to practice, people can through this way to relax for the pain inside.

The fourth stage is the classical period, in second Century, this time there is a representative book is "Yoga Sutra" and the "Bhagavad Gita", which appeared earlier is the "Bhagavad Gita", it makes the body of science and religion in yoga before Vedic philosophy together, and to elaborate behavior, knowledge and belief to equal attention, three must be combined with practice. After India and 
Zhepatanjia practice through their own perception of "Yoga Sutra" wrote a book, the book mainly discusses Yoga related theory, discusses the system to become the first classic yoga.

The fifth stage is after the classical period, until nineteenth Century, during this period there have been Tanduoluo yoga, has an important influence on modern yoga, Hatha Yoga has produced in the following. In addition, this period has 21 important classical works on yoga yoga, such as "Upanishads". The main difference between this period and before is to emphasize the practice of the practitioner to accept the reality, not to get rid of it.

The sixth period is modern yoga. It is popular with the development of capitalism. In nineteenth Century, Krishna, the founder of modern yoga, founded the yoga we saw today.

\section{Summary of Chinese Yoga}

\subsection{Origin of Chinese Yoga Culture}

Chinese yoga Chinese yoga can trace to the Western Han Dynasty, with the cultural and educational exchanges, yoga was introduced to Chinese, then slowly China cultural influence. From the period of classics and techniques can be seen in its effects on Chinese, such as "muscle-bone strengthening exercise" is influenced by the Yoga culture, and later the Tianzhu country massage method prevalent in the Tang Dynasty in the Song Dynasty and the Ming Dynasty, after the works were included in the. After the development of yoga in modern times, it began to spread through digital media. It entered the CCTV channel in 80s, and since then, it has been published in various magazines, which makes the public feel its charm more closely. Nowadays, small and large yoga hall has been set up in all parts of the country. The reason is that more and more people like this very cultural exercise. At the same time, they also play an important role in cultural communication.

\subsection{Development of Chinese Yoga Culture}

Since the introduction of yoga to China, different forms have been presented in the context of different periods. Early yoga with Buddhism combination, which is mainly reflected in China before the ceremony said, as mentioned before "and" Tianzhu country muscle-bone strengthening exercise massage techniques. Then the combination of yoga and Qigong, yoga practice in the use of gas injection, to a certain extent of the paper is too one-sided. Nowadays, it is mainly a form of fitness and entertainment. When we enter the shopping malls, we can always see related products, such as related costumes, videos and books. From a certain level of level, yoga and many people's lives have merged. According to the 2016 Yoga consumption white paper, there are more than 4 yoga centers on the Chinese market in 2016, and about 200000 training coaches. The training scale is also up to hundreds of thousands, and the number is increasing rapidly.

\section{Development Problems of Chinese Yoga}

\subsection{Confusion of Yoga Essence}

Yoga is the original pursuit of the unity of body and mind, is a kind of cultural belief. But many yoga hall people will be regarded as a money-making tool, in the hope that the rise of yoga from fish and a wave of gold, they use the female beauty, hope to keep a good figure like psychology, yoga and weight loss combined with a series of words such as "Yoga" slogan to attract people eyeball, thus pull customers. These rely on the publicity of yoga to lose weight body most are not professional, they may have the essence of yoga is not clear during the related training does not give consumers the popularity of Yoga knowledge and just stay at the surface of simple movement teaching. In addition, various kinds of misleading consumers are also on line, such as beauty yoga, body yoga. The essence of yoga has been lost by exaggerating its function while catering to the consumer. 


\subsection{Bad Yoga Place}

India was originally a yogi yoga meditation in nature and feeling, the surrounding environment is going to a certain extent, and now, many in the city in different yoga training venues or the club, because of the various training funds pipe capacity, facilities are not the same, for example some yoga limited capital facilities is relatively simple, coupled with the training mode of teaching is perhaps lead to the whole training process is very crowded, due to personal hygiene habits, even in training Museum remained odor, just in such environment, the training of personnel how to experience the real Yoga fun, referred to this and practice yoga on breathing, relaxation, meditation is very conflict.

\subsection{Low Quality of Yoga Teachers}

Initially, yogi was originally a very focus on the connotation of culture, and in China only to meet the huge market demand, a number of clubs within a few days of training a yoga instructor, and then let the coach to teach students, many yoga instructor shallow knowledge of yoga, just stay in the body movement teaching, it's behind the culture and practice essence fully understand, resulting in yoga culture has not been spread in Chinese health.

\section{Relevant Suggestions of Chinese Yoga Development}

\subsection{Multifaceted Combination of Yoga Culture}

Our country now emphasizes the cultural strategy, the spread of Yoga culture also has a certain significance to improve the quality of the citizens, the official, the relevant knowledge in the media should popularize yoga, yoga history analysis, let the public understand the meaning of the original yoga during development, combined with the country the traditional culture, such as Qigong, meditation, to innovate on it, make it become a kind of new culture. For Yoga institutions, the popularity of Yoga culture should not be neglected in the process of teaching. Only by improving their service quality and specialization can we improve their competitiveness in the market.

\subsection{Optimize Facilities and Training Methods}

A good place to practice yoga is the necessary condition, yoga Museum institutions can innovate in the venues, such as the establishment of outdoor venues or the venue set up in the woods, this can not only meet the needs of consumers, and more fit the essence of yoga. In addition, on the scale of training, we should control the number of people and create a relatively relaxed and open environment, making the whole teaching achieve the desired purpose.

\subsection{Setting the Threshold to Improve the Quality of Yoga Teachers}

The yoga instructor yoga for cultural heritage is very important, for now the yoga instructor uneven phenomenon, the most effective way is to ask the coach staff with relevant professional qualification certificate, the official must promulgate relevant laws to regulate the market, for the purposes of institutions should have long-term development concept, so to hire people who have professional qualification certificate of the coaching staff, and encourage coaches to continue learning related knowledge, such as physiology, psychology and education etc.. Training the staff in a solid basic knowledge to achieve the goal of spreading the essence of Yoga culture.

\section{Conclusion}

In the great wave of Yoga popularization, we should not consider it as a fast elimination product, but we should savor the culture that has been precipitated for thousands of years. At the same time, we should also integrate Chinese culture into yoga to make it more attractive, without losing the original meaning of yoga. 


\section{References}

[1] Chen Lixia, Shi Bing, Zhang Xiping. Study on the Course of Chinese Modality of Yoga in China [J]. China Sport Science, 2009, 29(7): 84-91.

[2] Wang Hong, Wang Yajing. Yoga culture and the Chinese of Yoga [J]. Sichuan Sports Science, 2012(6): 82-84.

[3] Yan Liping, Tian Biao. Sociological inspiration on yoga popularity [J]. Journal of Shandong Institute of Physical Education and Sports, 2013, 29(4): 31- 34.

[4] Wei Yanli. Questionings to theViewpoint That Daoyin Gymnastics of Ancient China had been Influenced by Yoga of Ancient India [J]. Journal of Henan Normal University (Philosophy and Social Sciences), 2015, 42(5): 102-106. 